Www.jmscr.igmpublication.org Impact Factor 5.84

Index Copernicus Value: 71.58

ISSN (e)-2347-176x ISSN (p) 2455-0450

crossref DOI:_https://dx.doi.org/10.18535/jmscr/v5i11.202

Journal Of Medical Science And Clinical Research

IGM Publication

An official Publication of IGM Publication

\title{
Study on Socio Cultural and Maternal Factors in Relation to LBW Babies and Their Immediate Outcome
}

\author{
Authors \\ Nasreen Ali ${ }^{1}$, Budhia Majhi \\ ${ }^{1}$ Junior Resident, ${ }^{2}$ Assistant Professor \\ Department of Pediatrics, M.K.C.G Medical College, Berhampur, Ganjam, Odisha-760004, India
}

\begin{abstract}
A baby's weight at birth is a strong indicator of maternal and newborn health and nutrition. Being undernourished in the womb increases the risk of death in the early months and years of a child's life. The incidence of low birthweight, defined as the proportion of newborns weighing less than 2,500 grams, is monitored through both health system surveillance and household surveys. In 2013, nearly 22 million newborns - an estimated 16 per cent of all babies born globally that year-had low birthweight. In south Asia it is as high as 28 per cent. At 28\%, India had the third highest percentage of LBW newborns, behind only Mauritania (35\%), Pakistan and Yemen (32\% each).

The present study was conducted in the SNCU of MKCG medical college and hospital to evaluate the various socio cultural and maternal factors leading to low birth weight (LBW) babies and complication.

Keywords: Nutrition, Pregnancy complications, Literacy, LBW.
\end{abstract}

\section{Introduction}

A baby's weight at birth is a strong indicator of maternal and newborn health and nutrition. Being undernourished in the womb increases the risk of death in the early months and years of a child's life. India had the third highest percentage of LBW newborns as per global scenario. The prevalence of LBW in Odisha is $17 \%$ but some districts like Kandhamal have LBW as high as $42 \% .{ }^{[1]}$ This study will help to know the incidence and causes of LBW in southern Odisha.

Socio-cultural and Maternal factors contributing factors for LBW are multifaceted and include factors such as maternal age, poor maternal nutritional status, and non-pregnant weight, gestational age, intervals between pregnancies, parity, educational status, violence during pregnancy, lack of antenatal care (ANC) and very low socio-economic status. In India, low body mass index (BMI), short stature, anemia and/or other micronutrient deficiencies are known to increase the risk of giving birth to a baby with LBW. The nutritional status of a pregnant woman can be affected by many factors including low socio-economic status, higher parity and short inter-pregnancy interval. Women with low socioeconomic status are more likely to have inadequate food intake, unhygienic housing and lack of sanitation, reduced ability to seek medical care and purchase medicine/supplements, which then affects the birth weight of their infants. The incidences of placenta previa and malpresentation increases with high parity and these complications may predispose a women to give birth to an infant 
with LBW. Maternal nutrient stores may deplete as a result of short inter-pregnancy intervals thus may reduce the birth weight of an infant.

More effort is needed to identify women at risk of preterm labor and support them to give birth in a health facility that can offer extra care when needed, such as support for adequate feeding with breast milk, continuous skin to skin contact, antibiotics, and antenatal corticosteroids. To do this, it is critical that families, communities and health care workers value small babies so that they receive the life-saving care they need. To turn the tide on these preventable deaths, we need action across the spectrum of care from adolescence and preconception, pregnancy, the safe management of labor and delivery, and effective immediate and later postnatal care.

A safe and healthy start to life is at the heart of human capital and economic progress in every country, making care for small babies an essential investment in both the short- and long-term. As government leaders, civil society organizations, health workers, families, communities and other partners come together to enact change, we can prevent babies from being born too early and too small, and ensure that small babies get the critical life-saving care and nurturing they need.

\section{Material and Methods}

The study was conducted in the SNCU in year 2015-2017. The sample size was determined based on the prevalence of LBW in Odisha. Using $17 \%$ as prevalence and $10 \%$ as allowable error, using the formula $n=4 P Q / D^{2}$ the sample size was calculated to be 1952. From which 106 fell under the exclusion criteria of multiple babies, still born or with congenital defects hence were excluded from the study. Total admissions 1846, It included 748 LBW babies admitted with weight less than $2.5 \mathrm{~kg}$. Information such as name of mother, age, parity, pre-pregnancy weight, hemoglobin levels, bad obstetric history pre eclampsia, fetal distress, Socio-economic status, education and nutritional status were recorded. These results were compared with the rest 1098 babies with normal birth weight who were considered to be control.
The data collected were entered in the SPSS PC format and validated for internal consistency. For categorical variables, significant differences in proportions between the cases and controls were identified by the finding out Odds ratio,95\% confidence level and $\mathrm{P}$ value from Chi square test.

\section{Results}

Out of 1846 admissions, 748 Babies were categorized as LBW babies this constitutes $40 \%$ of the total neonatal admissions. The female to male ratio was $1: 1.68$ and showing that male are more predispose. (Table 1)Among the 577 preterm $70 \%$ were appropriate for date. This indirectly hints towards major contribution of environmental factors on the growing fetus in the later half of pregnancy. Most of the babies (41\%) were having a gestational maturity of 28 to 32 weeks .and belonged to mothers aged between 21 to 25 years. $71 \%$ of the low birth weight babies were results of pregnancy virtually receiving no or infrequent antenatal care. Majority of the mothers in this study were primipara. $40 \%$ of the mothers belonged to low SES. Illiterate mothers are at an increased risk of having LBW babies (60\%). This is mainly due to lack of health awareness and poor receptivity of health facility. As the education of the mother increases, the incidence of LBW decreases. $67 \%$ of the mothers who gave birth to LBW babies had done some kind of heavy work during their gestation. The protein intake deficit is $50 \%$.About $2 / 3 \mathrm{rd}$ of the LBW babies were outcome of pregnancies in mother weighing below $50 \mathrm{~kg}$ (Table 2). Hence maternal malnutrition is definitely a contributor to fetal malnutrition. Lower the hemoglobin of the mother, smaller the birth weight. Pregnancy complications like antipartum hemorrhage, pre eclamsia, severe anemia, threatened abortion and malaria directly contributes towards LBW prevalence (Table 3). The commonest neonatal problems encountered in LBW population were hyperbilirubinemia, followed by sepsis and asphyxia (Table 4). Incidence of both morbidity and mortality in LBW babies is more in male $56 \%$ and $23 \%$ respectively. The neonatal mortality 


\section{JMSCR Vol||05||Issue||11||Page 30995-30999||November}

turned out to be $31 \%$ in the present series. Neonatal infection ranked one in the list of causes and perinatal asphyxia being the 2 nd commonest cause (Table 5). Thus gender of the baby, preterm of gestation. gestational age $(\mathrm{GA})<32$ weeks, maternal age $(\mathrm{MA})<25$ years, maternal weight $(\mathrm{MW})<50 \mathrm{~kg}$, primi parity, $\mathrm{ANC}<3$, education of the mother $<=10$,low SES and heavy work load during pregnancy have high odds of LBW baby (Table 6).

Table 1.Sample Distribution According to Sex

\begin{tabular}{|l|c|c|c|}
\hline & NBW(1098) & LBW(748) & Total $(1846)$ \\
\hline Male & $636(34 \%)$ & $469(25 \%)$ & 1105 \\
\hline Female & $462(25 \%)$ & $279(15 \%)$ & 741 \\
\hline
\end{tabular}

Table 2.Sample Distribution of Average Nutrient Intake during Third Trimester in Comparison with RDA in Mothers of LBW Babies

\begin{tabular}{|l|c|c|c|}
\hline Nutrients/Day & RDA & Intake & Deficit \\
\hline Calorie(Kcal) & 2175 & 1541 & $643(30 \%)$ \\
\hline Protein(gm) & 65 & 32 & $33(50 \%)$ \\
\hline Calcium(mg) & 1000 & 701 & $299(30 \%)$ \\
\hline Iron(mg) & 38 & 26 & $12(31 \%)$ \\
\hline Folic acid & 400 & 256 & $144(36 \%)$ \\
\hline Fat $($ gms) & 30 & 22 & $8(26 \%)$ \\
\hline
\end{tabular}

Table 3 Sample Distribution of Various Pregnancy Complications in LBW and its Statistical Importance

\begin{tabular}{|l|c|c|c|c|c|}
\hline Complications & NBW(1098) & LBW(748) & $\begin{array}{l}\text { Odds } \\
\text { Ratio }\end{array}$ & $\begin{array}{c}\text { 95\% Confidence } \\
\text { Interval }\end{array}$ & P Value \\
\hline APH & 96 & 211 & 4.1011 & 3.1525 to 5.3353 & $\mathrm{P}<0.0001$ \\
No APH & 1002 & 537 & & & \\
\hline Pre Eclampsia & 85 & 108 & 2.0111 & 1.4885 to 2.7172 & $\mathrm{P}<0.0001$ \\
No Pre Eclampsia & 1013 & 640 & & & \\
\hline Malaria & 78 & 176 & 4.0237 & 3.0241 to 5.3537 & $\mathrm{P}<0.0001$ \\
No Malaria & 1020 & 572 & & & \\
\hline Anaemia(<=10gm\%) & 317 & 508 & 5.2149 & 4.2631 to 6.3791 & $\mathrm{P}<0.0001$ \\
No Anaemia & 781 & 240 & & & \\
\hline UTI & 74 & 152 & 3.5291 & 2.6259 to 4.7429 & $\mathrm{P}<0.0001$ \\
No UTI & 1024 & 596 & & & \\
\hline Thr. Abortion & 67 & 110 & 2.6531 & 1.9277 to 3.6514 & $\mathrm{P}<0.0001$ \\
No Thr. Abortion & 1031 & 638 & & & \\
\hline
\end{tabular}

Table 4.Sample Distribution of Morbidity Pattern in LBW

\begin{tabular}{|l|c|c|c|}
\hline Complications & Male(416) & Female(204) & Total \\
\hline Sepsis & 101 & 60 & $161(26 \%)$ \\
\hline Asphyxia & 85 & 51 & $136(22 \%)$ \\
\hline Hyperbilirubinemia & 167 & 74 & $241(39 \%)$ \\
\hline Pneumonia & 12 & 60 & $18(3 \%)$ \\
\hline RDS & 34 & 8 & $42(7 \%)$ \\
\hline Hypoglycemia & 12 & 2 & $14(2 \%)$ \\
\hline Hypothermia & 5 & 3 & $8(1 \%)$ \\
\hline
\end{tabular}


Table 5.Sample Distribution of Mortality Pattern in LBW

\begin{tabular}{|l|c|c|c|}
\hline Causes & Male(172) & Female(67) & Total(239) \\
\hline Asphyxia & 48 & 22 & $70(29 \%)$ \\
\hline Infection & 54 & 42 & $96(40 \%)$ \\
\hline Hypothermia & 12 & 8 & $20(8 \%)$ \\
\hline RDS & 30 & 12 & $42(18 \%)$ \\
\hline NEC & 2 & 0 & $2(1 \%)$ \\
\hline Unknown & 5 & 4 & $9(4 \%)$ \\
\hline
\end{tabular}

Table 6.Showing Various Risk Factors of LBW and their Statistical Relation

\begin{tabular}{|l|c|c|c|c|c|}
\hline Risk Factors & Case(LBW) & $\begin{array}{c}\text { Control } \\
\text { (NBW) }\end{array}$ & $\begin{array}{c}\text { Odds } \\
\text { Ratio(OR) }\end{array}$ & $\begin{array}{c}95 \% \\
\text { Confidence } \\
\text { Interval(CI) }\end{array}$ & P Value \\
\hline Sex(M/F) & 469 & 636 & 1.2211 & $1.0092-1.4775$ & 0.0399 \\
\hline Term(P/T) & 579 & 462 & & & \\
\hline GA(<32/>32) & 171 & 603 & 4.1105 & $3.3386-5.0608$ & $<0.0001$ \\
& 317 & 308 & 1.8865 & $1.5509-2.2947$ & $<0.0001$ \\
\hline MA(<=25/>25) & 431 & 790 & & & \\
\hline MW(<=50/>50) & 261 & 656 & 2.6270 & $2.1672-3.1843$ & $<0.0001$ \\
& 573 & 414 & 5.4097 & $4.3908-6.6651$ & $<0.0001$ \\
\hline Parity(Primi/Multi) & 471 & 684 & & & \\
\hline ANC(<3/>=3) & 277 & 905 & 7.9732 & $6.4315-9.8845$ & $<0.0001$ \\
& 529 & 403 & 4.1657 & $3.4118-5.0863$ & $<0.0001$ \\
\hline SES(Low/Not) & 219 & 695 & & & \\
\hline Education(<=10/>10) & 305 & 444 & 1.0141 & $0.8393-1.2253$ & 0.8845 \\
& 443 & 654 & & & \\
\hline Work Loa(Heavy/ & 106 & 364 & 2.6478 & $2.0778-3.3741$ & $<0.0001$ \\
\hline Normal) & 503 & 290 & 5.7203 & $4.6681-7.0096$ & $<0.0001$ \\
\hline
\end{tabular}

\section{Discussion}

In our study the appropriate statistical test showed the significant correlation coefficient $(\mathrm{P}=0.03)$ between these opines LBW outcome is more in male when compared to female. Which is against the general observation that females have lower birth weight compared to males ${ }^{[2]}$. The average nutrients intake per day is significantly less in all categories but protein intake is less by $50 \%$, mostly due to cultural belief of not taking non vegetarian diet on various occasions. Thus reducing protein rich diet in pregnancy which promotes optimum fetal growth. A study by Anisa M. Durrani et al in Effect of maternal dietary intake on the weight of the newborn in Aligarh city, India ${ }^{[3]}$ concluded that the dietary intake during all trimesters of pregnancy were significantly associated with the birth weight. In a study by Helen L. Guyatt in Impact of Malaria during Pregnancy on Low Birth Weight in SubSaharan Africa $^{[4]}$ which showed that malaria during pregnancy can result in low birth weight (LBW), an important risk factor for infant mortality which was also seen in our study. The study by D.Saminathan et al in Incidence, Mortality Pattern, and Outcome of Low Birth Weight Babies Admitted in a Rural Tertiary Care Center: A Retrospective Study ${ }^{[5]}$ observed that only $6.72 \%$ (241) babies died. Thus proving that timely intervention, better awareness and interaction with obstetricians, timely resuscitation by trained personnel, adequate manpower, use of 
antenatal steroids, surfactant, continuous positive airway pressure ventilation, and close monitoring of LBW babies results in better outcome.

Maternal and intrauterine environmental factors play a great role in the genesis of LBW babies in a large percentage of cases and most of these factors can be prevented by proper ANC, good nutrition, immunization and health education to mother. In view of its importance, birth weight has been included as one of the twelve basic health indicators recommended by WHO.

\section{Conclusion}

The high incidence of LBW babies is directly related to the maternal factors like young age and primiparity, multiparity, gestational age and amount of workload during pregnancy, illiteracy, poor nutrition, lack of antenatal care and pregnancy complications. Hence proper measures like discouraging early marriage, thrust on female literacy, health education for all; so that we can build up a nutritionally sound adolescent girl and an expectant mother.

\section{Reference}

1. According Odisha HMIS Analysis Report 2013

2. According to National Family Health Survey (NFHS) data of 2005-06

3. Durrani AM, Rani A. Effect of maternal dietary intake on the weight of the newborn in Aligarh city, India. Nigerian medical journal: jSournal of the Nigeria Medical Association. 2011 Jul;52(3):177.

4. Guyatt HL, Snow RW. Impact of malaria during pregnancy on low birth weight in sub-Saharan Africa. Clinical microbiology reviews. 2004 Oct 1;17(4):760-9.

5. Saminathan D, Mythili B, Ramesh E, Zacharias AM. Incidence, Mortality Pattern, and Outcome of Low Birth Weight Babies Admitted in a Rural Tertiary Care Center: A Retrospective Study. 